\title{
From the Editors
}

With a host of interesting articles, this issue welcomes a large new group of exceptional scholars to our editorial board. We are delighted to be able to draw on their wealth of experience in public policy processes, policy analysis, bureaucratic politics and public management, American and comparative political institutions, political economy, democratic theory, regulation, taxation, governance, social networks and research methods, as well as substantive domains such as education, social welfare, and urban and health policy. The new board members are as follows:

Michael Bailey, Georgetown University, USA

Jens Blom-Hansen, Aarhus University, Denmark

Daniel Carpenter, Harvard University, USA

Joshua Clinton, Vanderbilt University, USA

Keith Dowding, Australian National University, Australia

Fabio Franchino, University of Milan, Italy

Sean Gailmard, University of California, Berkeley, USA

Francesca Gains, University of Manchester, UK

Mark Hallerberg, Hertie School of Governance, Germany

William Howell, University of Chicago, USA

Christopher Kam, University of British Columbia, Canada

Philip Keefer, World Bank

Nolan McCarty, Princeton University, USA

M. Jae Moon, Yonsei University, South Korea

Karen Mossberger, Arizona State University, USA

Michael Neblo, Ohio State University, USA

Paul Quirk, University of British Columbia, Canada

Colin Scott, University College Dublin, Ireland

Betsy Sinclair, Washington University in St. Louis, USA

Craig Volden, University of Virginia, USA

David Weimer, University of Wisconsin-Madison, USA

We thank them and the distinguished continuing members of our board for their support of the Journal of Public Policy. 